\title{
Valve-sparing root replacement for freestanding pulmonary autograft aneurysm after the Ross procedure
}

Thomas Ratschiller, MD, ${ }^{\mathrm{a}}$ Sames-Dolzer Eva, MD, ${ }^{\mathrm{a}}$ Wolfgang Schimetta, PhD, ${ }^{\mathrm{b}}$ Patrick Paulus, MD, Hannes Müller, MD, ${ }^{\mathrm{a}}$ Andreas Zierer, MD, ${ }^{\mathrm{a}}$ and Rudolf Mair, MD

\section{ABSTRACT}

Objective: Autograft dilatation is the main long-term complication following the Ross procedure using the freestanding root replacement technique. We reviewed our 25-year experience with the Ross procedure with a special emphasis on valvesparing reoperations.

Methods: From 1991 to 2016, 153 patients (29.6 \pm 16.6 years; $29.4 \%$ pediatric) underwent a Ross operation at our institution with implantation of the autograft as freestanding root replacement. The follow-up is $98.7 \%$ complete with a mean of $12.2 \pm 5.5$ years.

Results: Mortality at 30-days was 2.0\%. Echocardiography documented no or trivial aortic regurgitation in $99.3 \%$ of the patients at discharge. Survival probability at 20 years was $85.4 \%$. No case of autograft endocarditis occurred. Autograft deterioration rate was $2.01 \%$ per patient-year, and freedom from autograft reoperation was $75.3 \%$ at 15 years. A reoperation for autograft aneurysm was required in 35 patients $(22.9 \%)$ at a mean interval of $11.1 \pm 4.6$ years after the Ross procedure. A valve-sparing root replacement was performed in $77 \%$ of patients, including 10 David and 17 Yacoub procedures with no early mortality. Three patients required prosthetic valve replacement within 2 years after a Yacoub operation. At latest follow-up, $92 \%$ of all surviving patients still carry the pulmonary autograft valve. Freedom from autograft valve replacement was $92.1 \%$ at 15 years.

Conclusions: Using the David or Yacoub techniques, the autograft valve can be preserved in the majority of patients with root aneurysms after the Ross procedure. Reoperations can be performed with no early mortality, a good functional midterm result, and an acceptable reintervention rate. ( $\mathrm{J}$ Thorac Cardiovasc Surg 2018;155:2390-7)

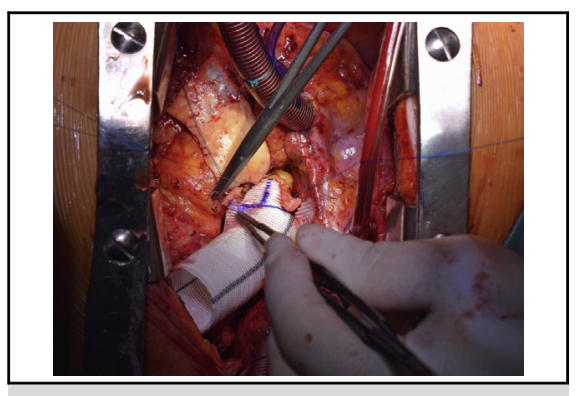

Yacoub procedure for pulmonary autograft aneurysm after the Ross operation.

\section{Central Message}

The David and Yacoub procedures enable preservation of the autograft valve in the majority of patients with root aneurysm after the Ross procedure.

\section{Perspective}

Autograft dilatation is the main long-term complication following the Ross procedure using the freestanding root replacement technique, and accounts for most reoperations. The David and Yacoub procedures for preservation of the autograft valve carry a low operative risk and provide a good midterm functional result with an acceptable rate of reintervention.

See Editorial Commentary page 2398.
The use of the pulmonary autograft as an aortic valve substitute, first proposed by Donald Ross in $1967,{ }^{1}$ provides a viable valve with excellent hemodynamics, ${ }^{2}$ a high resistance to infection, ${ }^{3,4}$ growth potential in children, low thrombogenicity, and therefore avoidance of

\footnotetext{
From the Departments of a Cardiothoracic and Vascular Surgery and ${ }^{\mathrm{c}}$ Anesthesiology and Intensive Care Medicine, Kepler University Hospital, Linz, Austria; and ${ }^{\mathrm{b}}$ Department of Applied Systems Research and Statistics, Johannes Kepler University, Linz, Austria.

Clinical Trial Registry Number: K-117-16.

Received for publication Oct 24, 2017; revisions received Dec 15, 2017; accepted for publication Jan 2, 2018; available ahead of print March 14, 2018.

Address for reprints: Thomas Ratschiller, MD, Department of Cardiothoracic and Vascular Surgery, Kepler University Hospital, Krankenhausstraße 9, Linz 4021, Austria (E-mail: Thomas.Ratschiller@gmx.at).

0022-5223/\$36.00

Copyright (c) 2018 by The American Association for Thoracic Surgery

https://doi.org/10.1016/j.jtcvs.2018.01.095
}

anticoagulation. Compared with homograft implantation and prosthetic valve replacement, the Ross procedure improves long-term survival and quality of life in young adults by avoidance of early degeneration and valverelated complications. ${ }^{5-7}$ Despite a low operative mortality, ${ }^{8-10}$ concerns remain regarding the possibility of complex reoperations on both the autograft and homograft. ${ }^{11}$ Progressive aortic root dilatation is increasingly recognized late after the Ross procedure, especially

Scanning this QR code will take you to the article title page. 


\section{Abbreviations and Acronyms \\ $\mathrm{CI}=$ confidence interval \\ $\mathrm{RVOT}=$ right ventricular outflow tract}

when the autograft was implanted as a freestanding root replacement. ${ }^{12}$ Experience with valve-sparing reoperations to salvage the autograft valve and to prevent prosthetic valve replacement remains limited. ${ }^{13-16}$ In this study, we reviewed our experience with the Ross procedure over 25 years with a special emphasis on valve-sparing reoperations.

\section{METHODS \\ Patients}

From January 1991 to December 2016, 153 patients (24.8\% female; $29.4 \%$ pediatric) underwent Ross operations at our institution with implantation of the autograft as a freestanding root replacement. The operative indications were in line with the American College of Cardiology and American Heart Association guidelines. ${ }^{17}$ The Ross operation was proposed to patients younger than 50 years and in select older patients if considered appropriate. Concomitant severe comorbidities, extensive coronary artery disease, severely depressed ventricular function, and structural defects of the pulmonary valve were considered contraindications for a Ross procedure.

In patients with a failing autograft, indications for surgery included neosinus dilatation of $50 \mathrm{~mm}$ or greater, a progressive increase in aortic diameter of greater than $5 \mathrm{~mm} /$ year, and severe valve regurgitation with symptoms of left ventricular dilatation or dysfunction. Calcifications, retraction, large fenestrations and severe prolapse of valve leaflets, valve stenosis, and informed patient refusal were considered contraindications for a valve-sparing reoperation. This retrospective investigation was approved by the Ethics Committee of the Kepler University Hospital (file number K-117-16) and patient consent was waived.

\section{Follow-up}

Follow-up was closed in December 2016, and it is $98.7 \%$ complete with a mean of $12.2 \pm 5.5$ years, yielding a cumulative total of 1845 patientyears. The mean echocardiographic follow-up was $10.5 \pm 5.8$ years. A retrospective review of prospectively collected data was performed using our institutional database. The clinical course and echocardiographic data were obtained from medical records, patient visits, telephone interviews, and communications with referring physicians. Patients were examined using transthoracic echocardiography before and after surgery and during regular follow-up visits. The severity of aortic regurgitation was classified as grades 0, I (trivial), II (mild), III (moderate), and IV (severe).

\section{Operative Technique}

Standard cardiopulmonary bypass with moderate hypothermia was conducted in all patients. The pulmonary valve was evaluated using thorough echocardiography and visual inspection at the beginning of the operation. The autograft was implanted as a freestanding (complete) root replacement in an intra-annular position with close interrupted or a running polypropylene suture. In adolescent and adult patients, the proximal suture line was reinforced with a strip of pericardium. The distal anastomosis was performed 2-3 $\mathrm{mm}$ above the commissures to keep the autograft short. The right ventricular outflow tract (RVOT) was reconstructed using a cryopreserved homograft. If one was not available, a Contegra or a Freestyle prosthesis (Medtronic, Minneapolis, Minn.) was used.
The techniques of valve-sparing root reconstruction have been described previously in detail. ${ }^{18,19}$ If the aortoventricular junction was dilated, the reimplantation technique according to David ${ }^{18}$ was favored to stabilize the annulus effectively. Additional measures included subcommissural annuloplasty, resuspension of commissures for cusp prolapse, and leaflet augmentation with autologous pericardium as required. Intraoperative transesophageal echocardiography was performed in all patients to assess valve function.

\section{Statistics}

Statistical analysis was performed using the R statistical software package, version 3.2.3. All data sets of continuous variables were checked for normal distribution (test of normality: Kolmogorov-Smirnov with Lilliefors significance correction, type I error $=10 \%$ ). Data sets of continuous variables without normally distributed data sets and of variables measured on ordinal scales were compared using the exact Mann-Whitney $U$ test, and data sets of categorical variables were compared using the Fisher exact test or chi-square test (with provision of adjusted residuals). Continuous variables are reported as means \pm standard deviations. If the data are considerably skewed, medians and quartiles are given in brackets. Timeto-event variables, depicted by Kaplan-Meier plots, were compared using the log-rank test. For the comparative depiction of the survival times of the study population and the total population, a matched-pair approach with age- and sex-related estimations of total population survival times (source: Statistik Austria; available at: http://www.statistik-austria.at) censored at 25 years was used. Cox regression (including a forward method based on the likelihood ratio approach) was used to investigate the influence of the following covariates on the time to aneurysm occurrence: bicuspid aortic valve, sex, aortic regurgitation, and age at first operation. The type I error was not adjusted for multiple testing; therefore, the results of inferential statistics are descriptive only.

\section{RESULTS}

\section{Patients}

Clinical and operative data are summarized in Table 1. The mean age of the study population was $29.6 \pm 16.6$ years, including 50 patients $(32.7 \%)$ older than 40 years. A cardiac operation had been performed previously in 39 patients $(25.5 \%)$. Aortic regurgitation was the most frequent indication for surgery $(56.2 \%)$. The study population included 34 patients $(22.2 \%)$ with a bicuspid aortic valve and 19 patients $(12.4 \%)$ with acute infective endocarditis.

\section{Operative Date and Postoperative Course}

The mean aortic cross-clamp time was $124 \pm 22$ minutes. Nineteen patients $(12.4 \%)$ underwent a combined procedure. Permanent pacemaker implantation was required in 7 patients $(4.6 \%)$ for atrioventricular block. However, 3 of those patients had undergone operations for endocarditis, and 2 procedures were redo operations. Echocardiography at discharge documented aortic valve regurgitation grade 0 -I in 150 patients $(99.3 \%$ ) and grade II in 1 patient.

\section{Mortality}

All-cause mortality at 30 days was $2.0 \%$ (3 patients). One child with critical congenital aortic stenosis and endocardial fibroelastosis died from cardiac failure. Sudden 
TABLE 1. Clinical and operative data of 153 patients undergoing a Ross operation with implantation of the autograft as freestanding root replacement

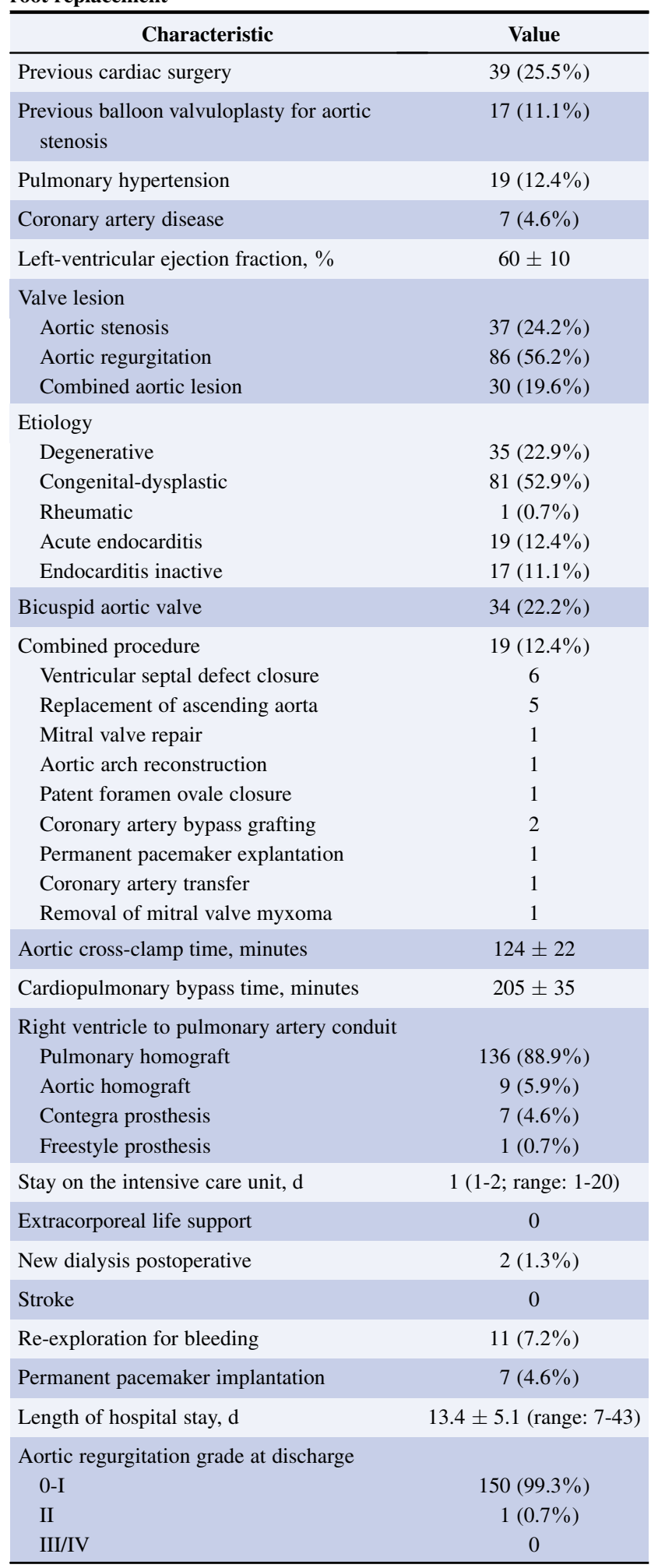

cardiac death from delayed cardiac tamponade occurred in 1 patient after discharge. One patient with acute endocarditis, complicated by renal failure, died 20 days after operation from gastrointestinal bleeding.

Overall mortality within the observational period was $9.8 \%$ (15 patients). Reasons for late death included chronic heart failure (3), infection (3), myocardial infarction (1), malignancy (1), trauma (1), and gastrointestinal bleeding associated with liver cirrhosis (1). The cause of death remained unknown for 2 patients.

Valve-related late mortality was $2.0 \%$ (3 patients; $0.16 \%$ per patient-year). All 3 patients died from chronic heart failure, including 1 drug-addict patient with recurrent tricuspid valve endocarditis.

The survival probability of the study population was $85.4 \%(95 \%$ confidence interval [CI], 77.6-93.9) at 20 years compared with $99.3 \%$ (95\% CI, 98.1-100.0) for the age- and sex-matched general population (Figure 1).

\section{Bleeding and Thromboembolic Events}

Freedom from bleeding complications was $97.9 \%$ (95\% CI, 95.6-100.0) at 15 years. Freedom from embolic events was $97.7 \%$ (95\% CI, 94.5-100.0) at 15 years. No cases of valve thrombosis affecting the homograft or autograft valve were observed.

\section{Reoperations on the Homograft}

A reoperation on the RVOT conduit was required in 14 patients $(9.2 \% ; 0.76$ per 100 patient-years $)$ at a mean interval of $8.5 \pm 5.0$ years (range, $0.6-16.2$ years) after the Ross procedure. Homograft stenosis was the indication for reoperation in 9 patients. Infective endocarditis occurred in 5 patients, including 3 patients with a history of endocarditis and 1 patient with intravenous drug abuse. The mean cardiopulmonary bypass time was $88 \pm 38$ minutes. Mortality at 30 days was $0 \%$. Freedom from reoperation on the RVOT conduit was $87.0 \%(95 \% \mathrm{CI}, 80.1-94.4)$ at 15 years.

Twelve patients $(7.8 \%)$ with homograft stenosis underwent transcatheter valve implantation (Melody; Medtronic). The overall percentage of reoperations and reinterventions on the RVOT was higher in the pediatric than in the adult patient cohort $(35.6 \%$ vs $6.5 \%$; $P<.001)$. Deterioration rates for the RVOT conduit for consecutive, adult, and pediatric patients were 1.25, 0.52, and 3.23 per 100 patient-years, respectively.

\section{Pulmonary Autograft Aneurysms}

During the study period, autograft dilatation of $50 \mathrm{~mm}$ or greater was confirmed with echocardiography or computed tomography, or both, in 39 patients $(25.5 \%)$. In the first decade after the Ross procedure, 1.2 aneurysms $(95 \%$ CI, 


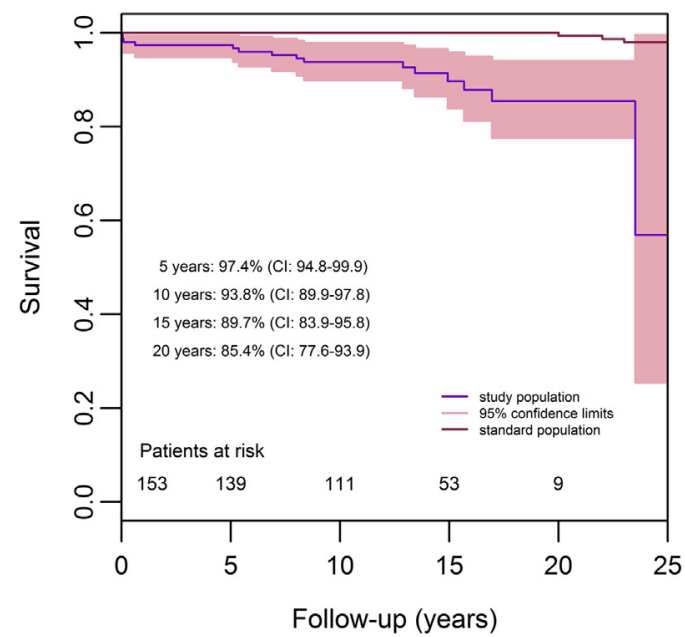

FIGURE 1. Survival probability of the study population compared to the age- and gender-matched general population. $C I$, Confidence interval.

0.3-1.3) developed per 100 patient-years; in the second decade, that number grew to 5.5 (95\% CI, 3.8-8.4). Cox regression analysis identified male sex as the only independent risk factor for autograft dilatation $(P=.019)$. Bicuspid aortic valve, aortic regurgitation, and age at first operation were not risk factors for progressive root dilatation.

\section{Reoperations on the Autograft}

A reoperation on the autograft was required in 37 patients $(24.2 \%$; 2.01 per 100 patient-years; mean age, $34.6 \pm 13.7$ years) at a mean interval of $10.9 \pm 4.7$ years (range, 1.4-18.6) after the Ross procedure. Freedom from autograft reoperation was $75.3 \%(95 \% \mathrm{CI}, 67.1-84.5)$ at 15 years (Figure 2) without significant difference between adult and pediatric patients $(P=.885)$.

Autograft dilatation was the indication for reoperation in 35 patients $(22.9 \%)$, including 16 patients with moderate to severe aortic regurgitation (Figure 3 ). In 27 of those patients $(77.1 \%)$, the autograft valve could be preserved with root reconstruction, and a conduit was primarily implanted in 8 patients. Isolated prosthetic valve replacement for severe aortic regurgitation owing to cusp prolapse without root dilatation was done in 2 patients. Concomitant procedures included homograft replacement in 3 patients and mitral valve replacement in 1 patient. Mortality at 30-days was $0 \%$. There was no case of endocarditis affecting the autograft during the study period.

\section{Valve-Sparing Reoperations}

In 27 patients with autograft dilatation $(54.7 \pm 4.2 \mathrm{~mm})$ but structurally normal valve leaflets, a valve-sparing reoperation was performed (Figure 4). Ten patients $(37 \%)$ had moderate to severe aortic regurgitation. In 5 patients $(18.5 \%)$, the valve-sparing operation was their third cardiac procedure.

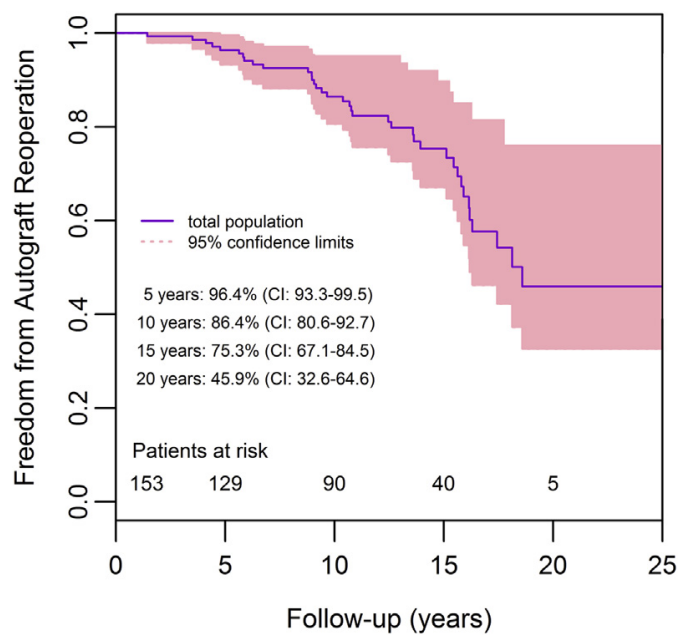

FIGURE 2. Freedom from autograft reoperation. $C I$, Confidence interval.

A Yacoub operation was performed in 17 patients, and a David operation was performed in 10 patients. Additional autograft cusp repair was necessary in 2 patients and included commissural resuspension for leaflet prolapse and commissurotomy with augmentation of the left and noncoronary leaflet using autologous pericardium.

The mean aortic cross-clamp time was $136 \pm 20$ minutes. None of the patients required permanent pacemaker implantation. In-hospital mortality was $0 \%$. Echocardiography at discharge documented aortic regurgitation grade 0 to I in 24 patients $(88.9 \%)$ and grade II in 2 patients.

One patient with low-output syndrome received a Berlin Heart EXCOR (Berlin Heart; Berlin, Germany) and underwent successful transplantation 262 days after device implantation.

Follow-up after valve-sparing reoperations is $100 \%$ complete with a mean of $4.6 \pm 3.1$ years (range, 0.1 10.2). During the study period, 3 patients underwent a mechanical conduit implantation for progressive aortic regurgitation, all after a Yacoub procedure. In the remaining patients, freedom from aortic regurgitation greater than grade II was $100 \%$ at 5 years. Freedom from autograft reintervention after a valve-sparing reoperation was $86.6 \%$ (95\% CI, 73.5-100.0) at 5 years. The survival probability after reoperation was $85.7 \%(95 \% \mathrm{CI}, 63.3-100.0)$ at 10 years. Clinical and operative data are presented in Table 2.

\section{Replacement of the Autograft Valve}

Replacement of the autograft valve with a prosthetic heart valve was performed in 13 patients $(8.5 \%$; 11 mechanical and 2 biological prostheses) at a mean interval of $11.3 \pm 5.5$ years after the Ross operation. Freedom from autograft valve replacement was $92.1 \%(95 \%$ CI, 86.797.9) at 15 years (Figure 5). In the remaining patients, freedom from aortic regurgitation greater than grade II 

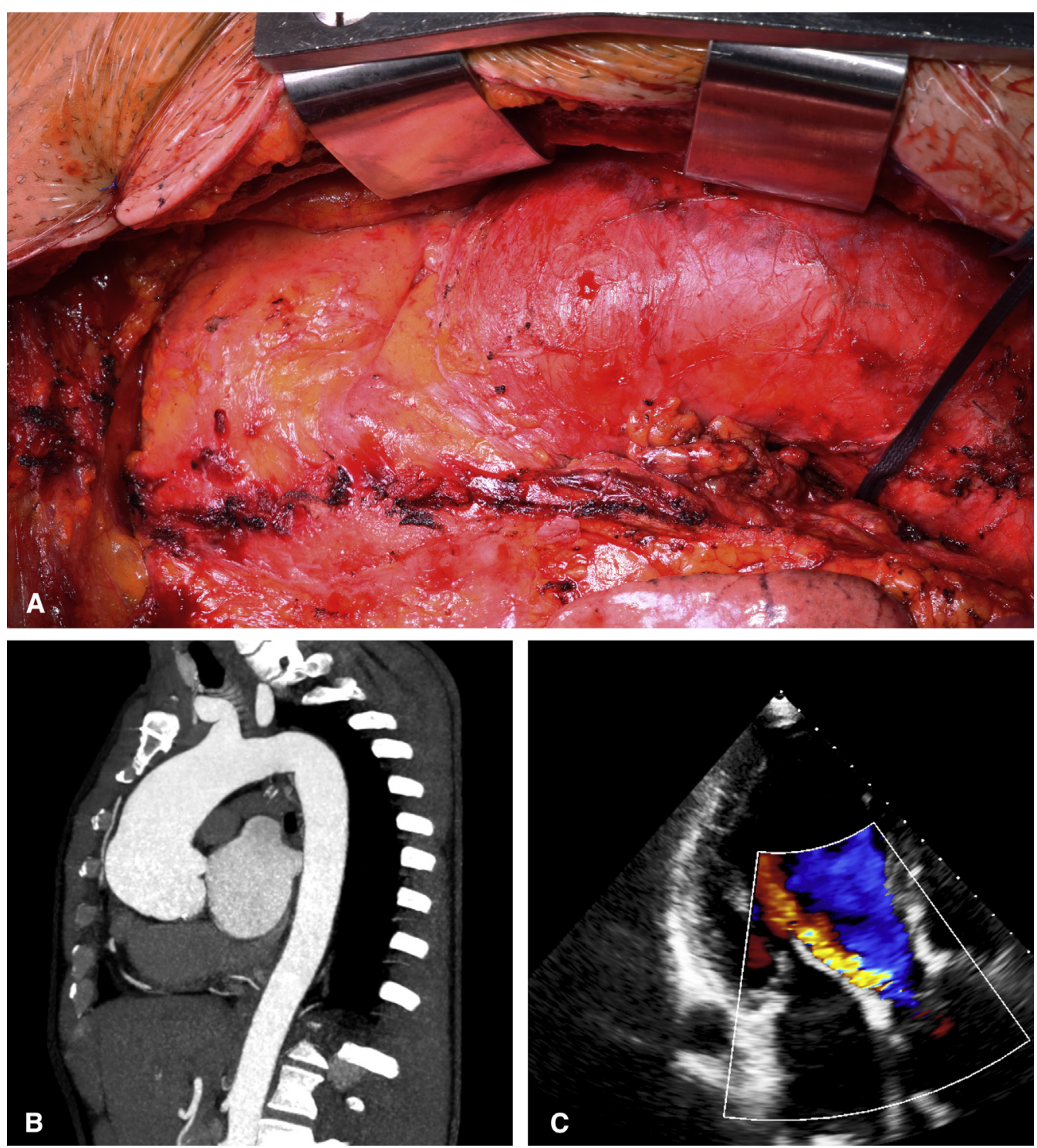

FIGURE 3. Autograft aneurysm $(56 \mathrm{~mm})$ in a patient who required reoperation 19.8 years after a Ross procedure. A, Intraoperative view. B, Preoperative computed tomography scan in sagittal projection. C, Preoperative echocardiography documenting moderate aortic regurgitation.

was $94.0 \%(95 \% \mathrm{CI}, 88.3-100.0)$ at 15 years. At latest follow-up, 127 patients $(92.0 \%)$ of 138 survivors still carry the autograft valve. The most recent echocardiography showed aortic regurgitation grade 0 to $\mathrm{I}$ in 114 patients $(89.8 \%)$, grade II in 8 patients $(6.3 \%)$, and grade III in 5 patients $(3.9 \%)$. None of the patients underwent a further reintervention after prosthetic valve replacement.

\section{DISCUSSION}

In the present study, we confirmed previous reports documenting a low operative mortality and an excellent early valve function of the Ross operation in selected children and adults. ${ }^{8-10}$ Contradictory to previous findings, ${ }^{6,8-10}$ long-term survival was reduced compared with the general population. However, half of late deaths were clearly not cardiac-related.

Despite the clear benefits in comparison to other valve substitutes, the need for reoperation remains the principal limitation of the Ross procedure. Late autograft failure owing to progressive aortic root dilatation has been recognized in a significant proportion of patients with implantation of the autograft as a freestanding root replacement. ${ }^{12}$ In the present study, 35 patients $(22.9 \%)$ were reoperated for autograft aneurysm at a mean interval of $11.1 \pm 4.6$ years after the Ross procedure. In addition, 4 patients with confirmed root dilatation $50 \mathrm{~mm}$ or greater are receiving close follow-up. Reoperations for aortic root aneurysm accounted for the majority $(94.6 \%)$ of all 

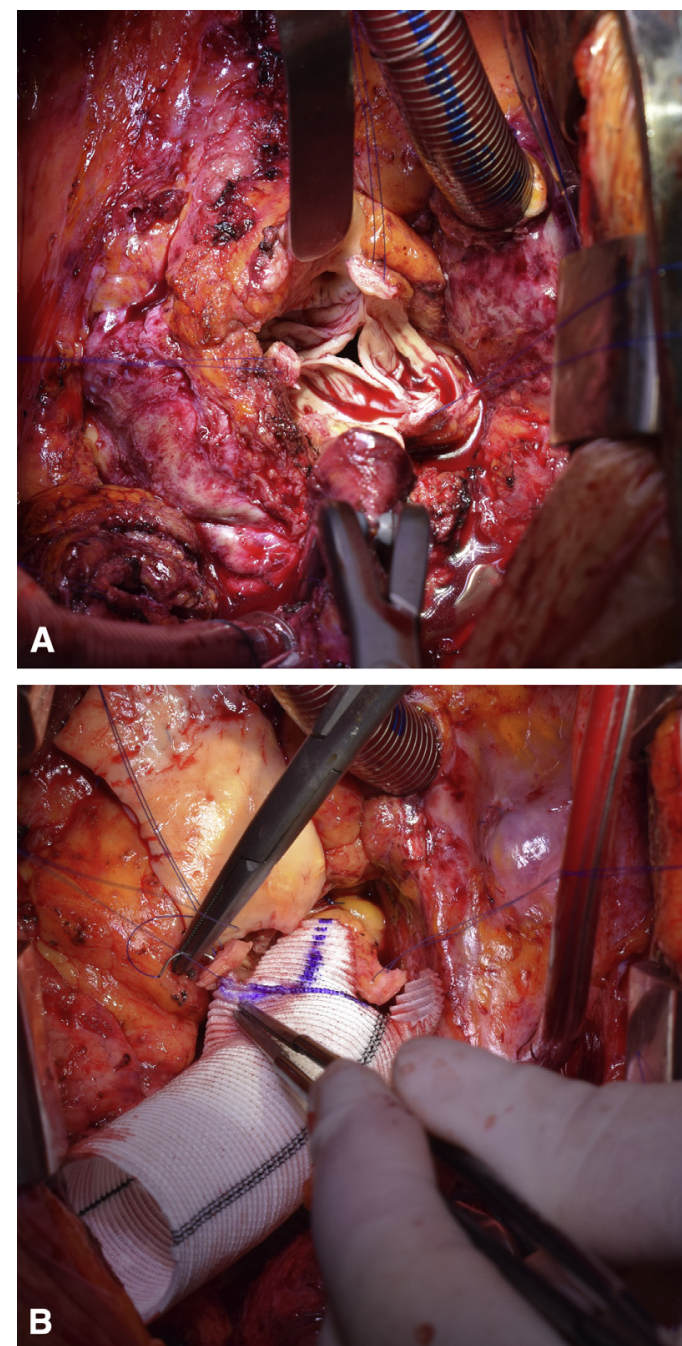

FIGURE 4. Valve-sparing reoperation for autograft aneurysm. A, Intraoperative view of the pulmonary autograft valve, displaying no degenerative leaflet changes. B, Yacoub procedure late after the Ross operation.

reinterventions needed on the autograft in our series, which is in accordance to previous data. ${ }^{12}$ In contrast to previous publications, bicuspid aortic valve, age, and primary diagnosis of aortic regurgitation were not identified as risk factors for autograft failure. ${ }^{3,10,12,20}$ Freedom from autograft reoperation at 15 years was $75.3 \%$, which is comparable to other series with implantation of the autograft as freestanding root replacement. ${ }^{9,12}$ The estimated risk for reoperation on the autograft in our series was $2.01 \%$ per patient-year. In a large meta-analysis, the autograft deterioration rate was $1.15 \%(95 \% \mathrm{CI}, 1.06-2.06)$ per patient-year. ${ }^{21}$ In most of the included articles, the follow-up time was limited compared with 12.2 years in our series. Clinically significant autograft dilation, however, occurs with increasing frequency late after the Ross operation, ${ }^{12}$ even if enlargement of the pulmonary root exposed to the systemic circulation can be detected with echocardiography within the first postoperative months. ${ }^{22}$
The majority of patients with failed autografts are still young at the time of reoperation. Implantation of a biologic valve or homograft exposes them to the risk of early degeneration, whereas mechanical valve replacement is associated with thromboembolic and hemorrhagic complications related to long-term anticoagulation. ${ }^{6,7}$ Moreover, young patients receiving a prosthetic heart valve have a significantly shorter life expectancy than the general population and inferior outcomes regarding survival and quality of life compared to patients with a pulmonary autograft. ${ }^{5-7}$

The David and Yacoub procedures are proven, reliable techniques to treat patients with primary aortic root aneurysm with a low early mortality, an excellent functional outcome, and a low rate of reintervention. ${ }^{18,19}$ However, experience with these procedures for autograft aneurysms after the Ross operation remains limited. ${ }^{13-16}$ To our knowledge, we are reporting the largest single-center experience. In case of severe prolapse or degeneration of valve leaflets, a conduit was primarily implanted. Reported results of leaflet plication or shortening either alone or in conjunction with root reconstruction have been unsatisfactory with a high rate of reintervention. ${ }^{14,15}$ The majority of our patients displayed little or no degenerative changes of valve leaflets. A valve-sparing root replacement could be therefore performed in $77 \%$ of patients, with only 2 patients requiring additional leaflet repair. Three patients underwent a reoperation for autograft dilatation in other institutions, and all of them received a prosthetic heart valve. One patient insisted on a mechanical conduit implantation to minimize the risk of a further reintervention.

The reported low operative mortality in our and in previous series indicates that root reconstruction, even in patients after a Ross operation with sometimes multiple previous interventions, can be performed safely in experienced centers. ${ }^{13,14}$ One of our patients could not be weaned from cardiopulmonary bypass after an uneventful root reconstruction with a cross-clamp time of 97 minutes for unknown reasons. This patient ultimately required a heart transplant and died 7 years after the reoperation from influenza type B pneumonia.

Three patients in our series required prosthetic valve replacement for aortic regurgitation, all within 2 years after a Yacoub procedure. In 2 of those patients, the functional result after root remodeling had been suboptimal with residual grade II aortic regurgitation at discharge, including $1 \mathrm{pa}-$ tient with leaflet augmentation by a pericardial patch. In the remaining patient, progressive annular enlargement caused recurrent severe aortic regurgitation. Freedom from reintervention after valve-sparing reoperations was $86.6 \%$ at 5 years, which corresponds to the results of a multicenter trial reporting $85 \%$ freedom from reintervention at 8 years in 70 patients after valve-sparing autograft reoperation. ${ }^{23}$ Some authors clearly favor the David procedure for a failed Ross to achieve durable annulus stabilization. Liebrich 
TABLE 2. Clinical and operative data of 27 patients receiving a valvesparing reoperation for autograft aneurysm

\begin{tabular}{|c|c|}
\hline \multicolumn{2}{|l|}{ Type of surgery } \\
\hline David operation & 10 \\
\hline Yacoub operation & 17 \\
\hline \multicolumn{2}{|l|}{ Preoperative aortic regurgitation grade } \\
\hline $0-\mathrm{I}$ & $15(55.6 \%)$ \\
\hline II & $2(7.4 \%)$ \\
\hline III/IV & $10(37.0 \%)$ \\
\hline Additional repair techniques & $4(14.8 \%)$ \\
\hline Resuspension of commissures & 1 \\
\hline Leaflet augmentation with pericardium & 1 \\
\hline Subcommissural annuloplasty & 2 \\
\hline Aortic cross-clamp time, minutes & $136 \pm 20$ \\
\hline Cardiopulmonary bypass time, minutes & $210 \pm 54$ \\
\hline Packed red cell transfusion, milliliter & $230 \pm 515(0 ; 0-300)$ \\
\hline Stay on the intensive care unit, $\mathrm{d}$ & 1 (1-2; range, $1-12)$ \\
\hline Extracorporeal life support & $1(3.7 \%)$ \\
\hline New dialysis postoperative & 0 \\
\hline Stroke & 0 \\
\hline Re-exploration for bleeding & $2(7.4 \%)$ \\
\hline Permanent pacemaker implantation & 0 \\
\hline Length of hospital stay, $d$ & $11.5 \pm 3.1$ (range: $7-19)$ \\
\hline \multicolumn{2}{|l|}{ Aortic regurgitation grade at discharge* } \\
\hline $0-\mathrm{I}$ & $24(92.3 \%)$ \\
\hline II & $2(7.7 \%)$ \\
\hline III/IV & 0 \\
\hline
\end{tabular}

*One missing patient due to ventricular assist device implantation.

et $\mathrm{al}^{13}$ reported excellent midterm results after the David procedure for autograft aneurysm with only 1 of 18 patients undergoing valve replacement during a mean follow-up of 3.2 years. Disadvantages of the David procedure in our experience include the need for a more extensive mobilization of the aortic root and a more difficult control of bleeding sites from the proximal suture line. One of our patients with a David operation required a pericardial patch repair for an iatrogenic lesion of the left main coronary artery. At latest follow-up, $92 \%$ of surviving patients in our study still carry the autograft valve, and echocardiography has documented no or trivial aortic regurgitation in $89.8 \%$ of those patients.

Recognizing the high incidence of aneurysm formation despite intra-annular implantation of the autograft and reinforcement of the proximal suture line, we currently use a modified implantation technique with reinforcement of the entire pulmonary root with a Dacron graft. Since 2015, we have used this technique in 16 adolescent and adult patients with an excellent early functional outcome corresponding to previous reports. ${ }^{24}$ Because of the limited follow-up, these patients were not included in the present

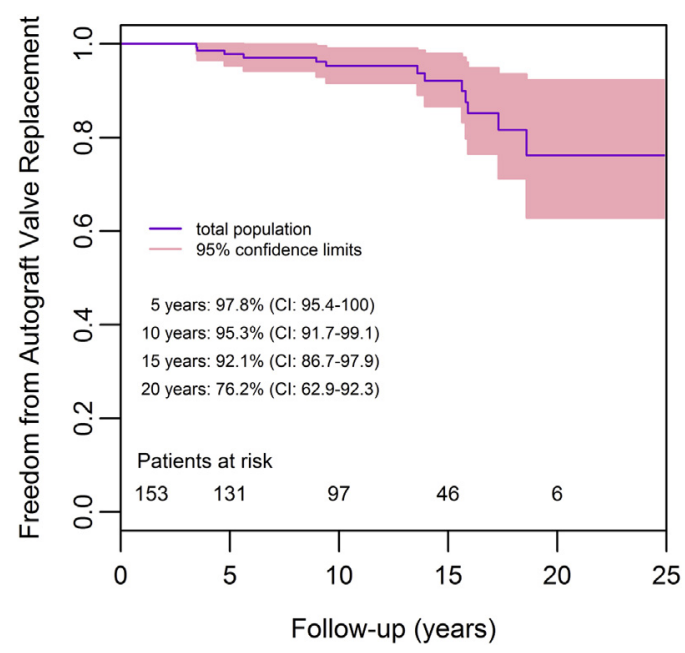

FIGURE 5. Freedom from prosthetic replacement of the autograft valve. $C I$, Confidence interval.

study. The subcoronary and root-inclusion techniques provide external autologous support to the pulmonary root without the use of prosthetic material. In a single-center, single-surgeon series with 501 patients, Sievers et $\mathrm{al}^{8}$ reported $94.7 \%$ freedom from autograft reoperation at 10 years following subcoronary autograft implantation. No reoperation for autograft dilatation was required after a mean follow-up of 5.9 years. ${ }^{8}$ Because of the technical complexity of the subcoronary valve transfer, it has been abandoned by most centers, including our own. ${ }^{21}$ Skillington et $\mathrm{al}^{25}$ reported $97 \%$ freedom from autograft reoperation at 15 years with minimal increase in aortic size over time among 204 patients using the root-inclusion technique. Because reoperations after the subcoronary or rootinclusion technique are often due to cusp prolapse associated with degenerative leaflet changes, prosthetic valve replacement may become necessary in most patients who need reoperation. ${ }^{8}$ More long-term data are clearly necessary to determine benefits and drawbacks of both techniques.

\section{Limitations}

Our study is a retrospective study with the inherent limitations. The follow-up after valve-sparing reoperations is limited, and long-term durability of repair is therefore not proven.

\section{CONCLUSIONS}

Aortic root dilatation occurs in a substantial proportion of patients late after the Ross procedure, and it accounts for the majority of reoperations on the autograft. Because degenerative leaflet changes are generally limited, prosthetic valve replacement can be avoided in most of these patients using a valve-sparing root replacement. The David and Yacoub procedures carry a low operative risk and provide a good 
midterm functional result with an acceptable rate of reintervention.

\section{Conflict of Interest Statement}

Authors have nothing to disclose with regard to commercial support.

\section{References}

1. Ross DN. Replacement of aortic and mitral valves with a pulmonary autograft. Lancet. 1967:2:956-8.

2. Sievers HH, Schmidtke C, Graf B. Hemodynamics of semilunar valves at rest and exercise at an average of more than two years after the ross procedure. $J$ Heart Valve Dis. 2001;10:166-9.

3. Elkins RC, Thompson DM, Lane MM, Elkins CC, Peyton MD. Ross operation: 16-year experience. J Thorac Cardiovasc Surg. 2008;136:623-30. 630.e621-5.

4. Ringle A, Richardson M, Juthier F, Rousse N, Polge AS, Coisne A, et al. Ross procedure is a safe treatment option for aortic valve endocarditis: long-term follow-up of 42 patients. Int J Cardiol. 2016;203:62-8.

5. El-Hamamsy I, Eryigit Z, Stevens LM, Sarang Z, George R, Clark L, et al. Longterm outcomes after autograft versus homograft aortic root replacement in adults with aortic valve disease: a randomised controlled trial. Lancet. 2010;376:524-31.

6. Andreas M, Wiedemann D, Seebacher G, Rath C, Aref T, Rosenhek R, et al. The Ross procedure offers excellent survival compared with mechanical aortic valve replacement in a real-world setting. Eur J Cardiothorac Surg. 2014;46:409-13.

7. Sharabiani MT, Dorobantu DM, Mahani AS, Turner M, Peter Tometzki AJ, Angelini GD, et al. Aortic valve replacement and the ross operation in children and young adults. J Am Coll Cardiol. 2016;67:2858-70.

8. Sievers HH, Stierle U, Charitos EI, Hanke T, Gorski A, Misfeld M, et al. Fourteen years' experience with 501 subcoronary ross procedures: surgical details and results. J Thorac Cardiovasc Surg. 2010;140:816-22. 822.e811-5.

9. Kouchoukos NT, Masetti P, Nickerson NJ, Castner CF, Shannon WD, DavilaRoman VG. The Ross procedure: long-term clinical and echocardiographic follow-up. Ann Thorac Surg. 2004;78:773-81.

10. Weimar T, Charitos EI, Liebrich M, Roser D, Tzanavaros I, Doll N, et al. Quo vadis pulmonary autograft-the Ross procedure in its second decade: a singlecenter experience in 645 patients. Ann Thorac Surg. 2014:97:167-74.

11. Stulak JM, Burkhart HM, Sundt TM, Connolly HM, Suri RM, Schaff HV, et al. Spectrum and outcome of reoperations after the Ross procedure. Circulation. 2010;122:1153-8

12. Bekkers JA, Klieverik LM, Raap GB, Takkenberg JJ, Bogers AJ. Aortic root reoperations after pulmonary autograft implantation. J Thorac Cardiovasc Surg. 2010;140:S58-63
13. Liebrich M, Weimar T, Tzanavaros I, Roser D, Doll KN, Hemmer WB. The David procedure for salvage of a failing autograft after the ross operation. Ann Thorac Surg. 2014;98:2046-52.

14. de Kerchove L, Boodhwani M, Etienne PY, Poncelet A, Glineur D, Noirhomme P, et al. Preservation of the pulmonary autograft after failure of the ross procedure. Eur J Cardiothorac Surg. 2010;38:326-32.

15. Luciani GB, Lucchese G, De Rita F, Puppini G, Faggian G, Mazzucco A. Reparative surgery of the pulmonary autograft: experience with Ross reoperations. Eur J Cardiothorac Surg. 2012;41:1309-14.

16. Brinkman WT, Herbert MA, Prince SL, Ryan C, Ryan WH. Redo autograft operations after the Ross procedure. Ann Thorac Surg. 2012;93:1477-81.

17. Nishimura RA, Otto CM, Bonow RO, Carabello BA, Erwin JP, Guyton RA, et al 2014 AHA/ACC guideline for the management of patients with valvular heart disease: a report of the American College of Cardiology/American Heart Association task force on practice guidelines. J Thorac Cardiovasc Surg. 2014;148: e1-132.

18. David TE, Feindel CM, David CM, Manlhiot C. A quarter of a century of experience with aortic valve-sparing operations. J Thorac Cardiovasc Surg. 2014;148: 872-9.

19. Yacoub MH, Gehle P, Chandrasekaran V, Birks EJ, Child A, Radley-Smith R Late results of a valve-preserving operation in patients with aneurysms of the ascending aorta and root. J Thorac Cardiovasc Surg. 1998;115:1080-90.

20. Settepani F, Kaya A, Morshuis WJ, Schepens MA, Heijmen RH, Dossche KM The Ross operation: an evaluation of a single institution's experience. Ann Thorac Surg. 2005;79:499-504.

21. Takkenberg JJ, Klieverik LM, Schoof PH, van Suylen RJ, van Herwerden LA Zondervan PE, et al. The Ross procedure: a systematic review and meta-analysis. Circulation. 2009;119:222-8.

22. David TE, Omran A, Ivanov J, Armstrong S, de Sa MP, Sonnenberg B, et al. Dilation of the pulmonary autograft after the Ross procedure. J Thorac Cardiovasc Surg. 2000;119:210-20.

23. Mookhoek A, de Kerchove L, El Khoury G, Weimar T, Luciani GB, Mazzucco A, et al. European multicenter experience with valve-sparing reoperations after the Ross procedure. J Thorac Cardiovasc Surg. 2015;150:1132-7.

24. Al Rashidi F, Bhat M, Hoglund P, Meurling C, Roijer A, Koul B. The modified Ross operation using a Dacron prosthetic vascular jacket does prevent pulmonary autograft dilatation at 4.5-year follow-up. Eur J Cardiothorac Surg. 2010;37: 928-33.

25. Skillington PD, Mokhles MM, Wilson W, Grigg L, Larobina M, O'Keefe M, et al Inclusion cylinder method for aortic valve replacement utilising the Ross operation in adults with predominant aortic stenosis - 99\% freedom from re-operation on the aortic valve at 15 years. Glob Cardiol Sci Pract. 2013;2013:383-94.

Key Words: Ross, pulmonary autograft, autograft dilatation, valve-sparing reoperation 